\title{
The Mathematics Genealogy Project Comes of Age at Twenty-one
}

\section{Colm Mulcahy}

\author{
Communicated by Steven J. Miller
}

\section{Addressing a Need (and Needing an Address)}

The Mathematics Genealogy Project (MGP) provides online $\mathrm{PhD}$ advisor and mathematical descendant information on over 200,000 mathematicians, a good fraction of the 825,000 authors on MathSciNet ${ }^{\circledR}$ and far more than the 2,700 biographies in the MacTutor History of Mathematics. It wasn't always like that.

In June 1984 the mathematics department at the University of Chicago hosted a conference marking the formal retirement of Irving Kaplansky (1917-2006), the Canadian algebraist who had been among the first to ace the Putnam exam, back in 1938. Kap, as he was known, was hardly ready to sail into the sunset: he was about to take over MSRI as its second director.

At the Chicago meeting much fuss was made of the fact that the honoree had supervised $55 \mathrm{PhDs}$, including Arlen Brown, Hyman Bass, Donald Ornstein, Joe Rotman, Judy Sally, and my own doctoral advisor, Alex Rosenberg. As I recall, a paper list was circulated that documented these, as well as their PhD students, and so on, to demonstrate Kaplansky's intellectual fecundity. Ironically, Kap's own advisor, Saunders Mac Lane, was also at that meeting. He just laughed when I buttonholed him in a corridor and commented that a list of all his descendants would be even more impressive.

Flash forward to the present day: in marked contrast to three decades ago, one's ancestors and descendants can easily be looked up at MGP online, ${ }^{1}$ as partially reflected

Colm Mulcahy is professor of mathematics at Spelman College, Atlanta. His e-mail address is colm@spe1man.edu.

${ }^{1}$ https: //www. mathgenealogy.org

For permission to reprint this article, please contact:

reprint-permission@ams . org.

DOI: http://dx.doi.org/10.1090/noti1512 in Figure 1. It shows that Kaplansky was the first of the 42 people whose theses Mac Lane supervised. Kap was also the most productive of these in terms of sheer numbers of descendants, a list that now tops 850. Mac Lane's own doctoral students include logician Anil Nerode, group theorist John Thompson, set theorist Robert Solovay, and algebraist David Eisenbud, each of whom has had over 100 descendants. Both Kaplansky's and Mac Lane's entries link to their MacTutor and MathSciNet listings, a feature common to many of the more noteworthy entries.

As with ordinary family trees, there are complications. For example, Eisenbud had two advisors. So did Mac Lane himself: Hermann Weyl and Paul Bernays. The Weyl line leads back through Hilbert and Lindemann to Klein, who also had two advisors. Following both lines, we encounter additional mathematical royalty: Lipschitz, Dirichlet, Poisson and Fourier, Lagrange and Laplace, Euler, d'Alembert, Plücker, and Gauss. Of course, Gauss has a lot to answer for: MGP's current estimate of his descendant count is about 78,000.

\section{Origins of the Species}

The Mathematics Genealogy Project was started twenty-one years ago, in 1996, by Harry Coonce, then a mathematician at Mankato State University in Minnesota. He was motivated in part by the difficulty he'd encountered when trying to determine the identity of his own "mathematical grandfather," i.e., his advisor's advisor. It turned out to be Einar Hille, but back then there was nowhere to look this up, neither a library nor a website. (Bruce Reznick recalls that Constance Reid in The Search for E. T. Bell said that she couldn't find his advisor's name.) Harry wrote to hundreds of departments that spring, and by the time the original MGP website was launched that September, he had 3,500 doctorate holders listed. 


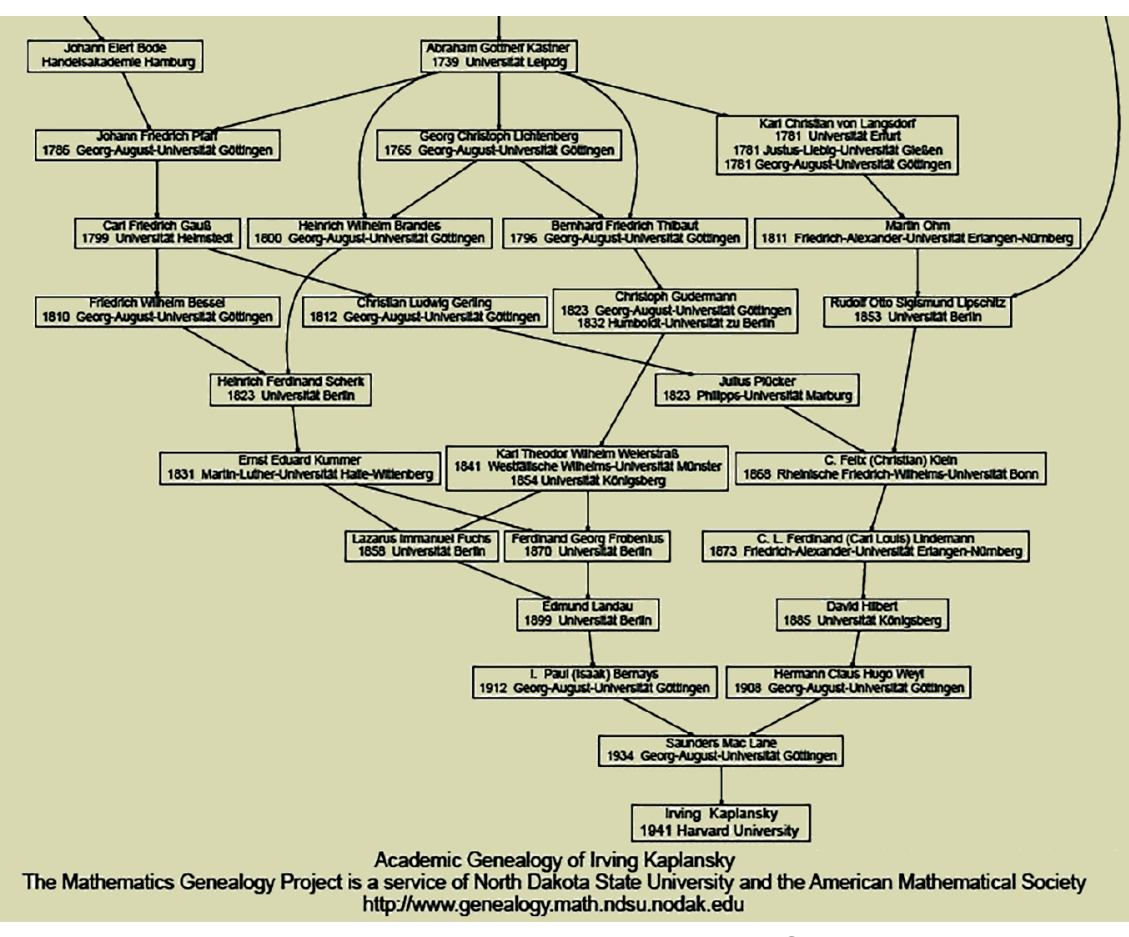

Figure 1. Irving Kaplansky's most recent ancestors from the Mathematics Genealogy Project; the full tree-only a part of which is shown here-now shows $\mathbf{8 5 0}$ descendants and extends back over seven hundred years.

Within a year, the project had grown to include 10,000 entries. When "A Labor of Love: The Mathematics Genealogy Project" by Allyn Jackson appeared in the Notices in 2007, the MGP had topped 100,000 people. By then Coonce had retired, found himself a new home at North Dakota State University, and taken onboard an undergraduate assistant who eventually took over the project: Mitch Keller, now a mathematician at Washington and Lee University in Lexington, Virginia.

From shaky beginnings with little or no funding, the project has become a mainstay of the mathematical community. It's now funded by the Clay Institute and the AMS, and in the summer of 2016 the MGP thesis count reached another landmark, surpassing 200,000 entries. Growth has been roughly linear, as shown in Figure 2.

While MGP collects information classified under one of several tags such as $\mathrm{PhD}$, DPhil, or DSc, no such distinction is made in this article. The first American $\mathrm{PhD}$ in mathematics (from Yale, 1861) was awarded to Arthur Wright; it was on satellite mechanics. Like over 75 percent of those individuals listed in MGP, yours truly included, Arthur had no descendants at all. The nature of doctoral work and the advisor system-not to mention the present-day expectation of having a $\mathrm{PhD}$ as a prerequisite for life in academia - arguably evolved out of older French and German models, and this all took time to take root.

\section{The Inclusion Principle}

The MGP has a very inclusive philosophy, welcoming submissions in mathematics education, statistics, computer science, or operations research, using a dropdown 2010 Mathematics Subject Classification list to select thesis areas. Hence, in theory, all dissertations in theoretical physics, geophysics, biology, astronomy, statistics, computer science, and/or operations research could end up being listed. There are already about 2,000 each flagged as "Systems theory, control" and "Biology and other natural sciences"; about 3,400 as "Operations research, mathematical programming"; and over 18,000 as "Computer science."

The "Extrema" page at the site lists the Top 75 Advisors (numerically), all of whom put Kaplansky in the shade, although many of those listed raise other questions. In first place is Chinese electrical engineer C.-C. Jay Kuo, whose own PhD from MIT is classified as "Information and communication, circuits." In the past quarter century at the University of Southern California, he is credited with supervising 137 doctorates. In second place is French numerical analyst Roger Temam with 119 students since 1972, and in third place is economist and computer scientist Andrew Whinston (with Erdős number 2), who has had 104 students since 1970. Kolmogorov, in position thirteen with $82 \mathrm{PhD}$ students, may be the first name recognized by most mathematicians.

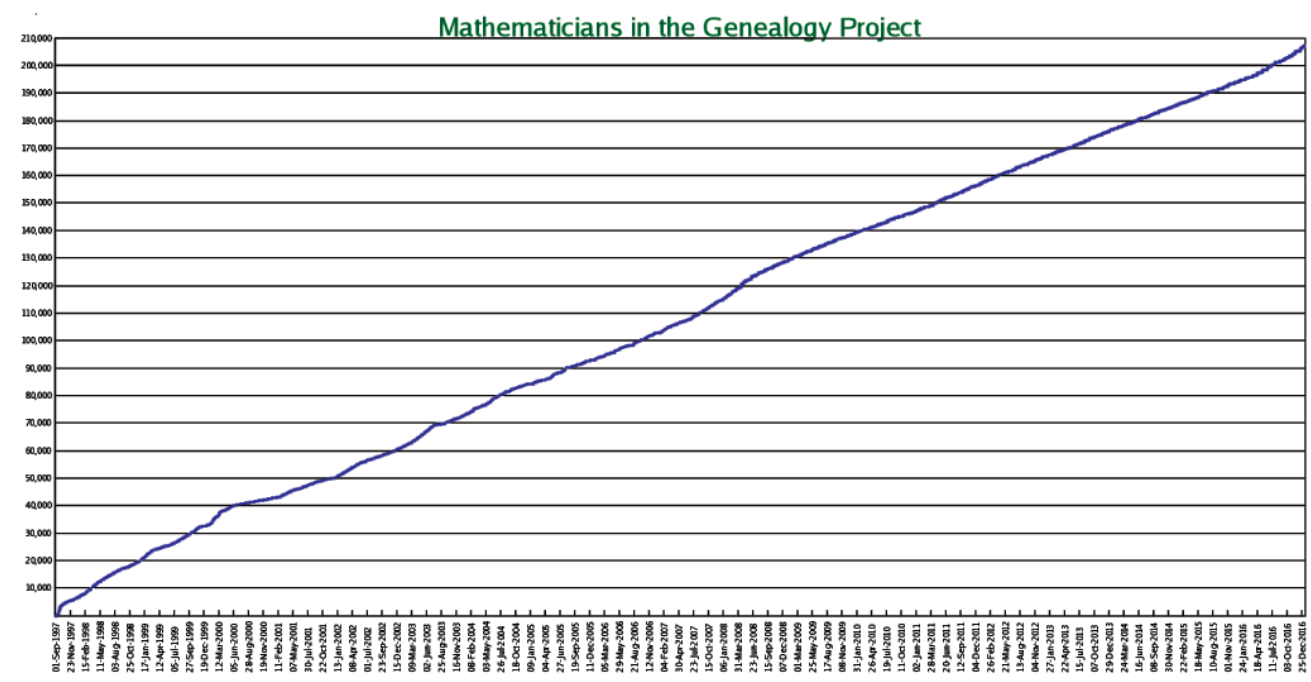

Figure 2. The growth of Math Genealogy listings. 


\section{COMMUNICATION}

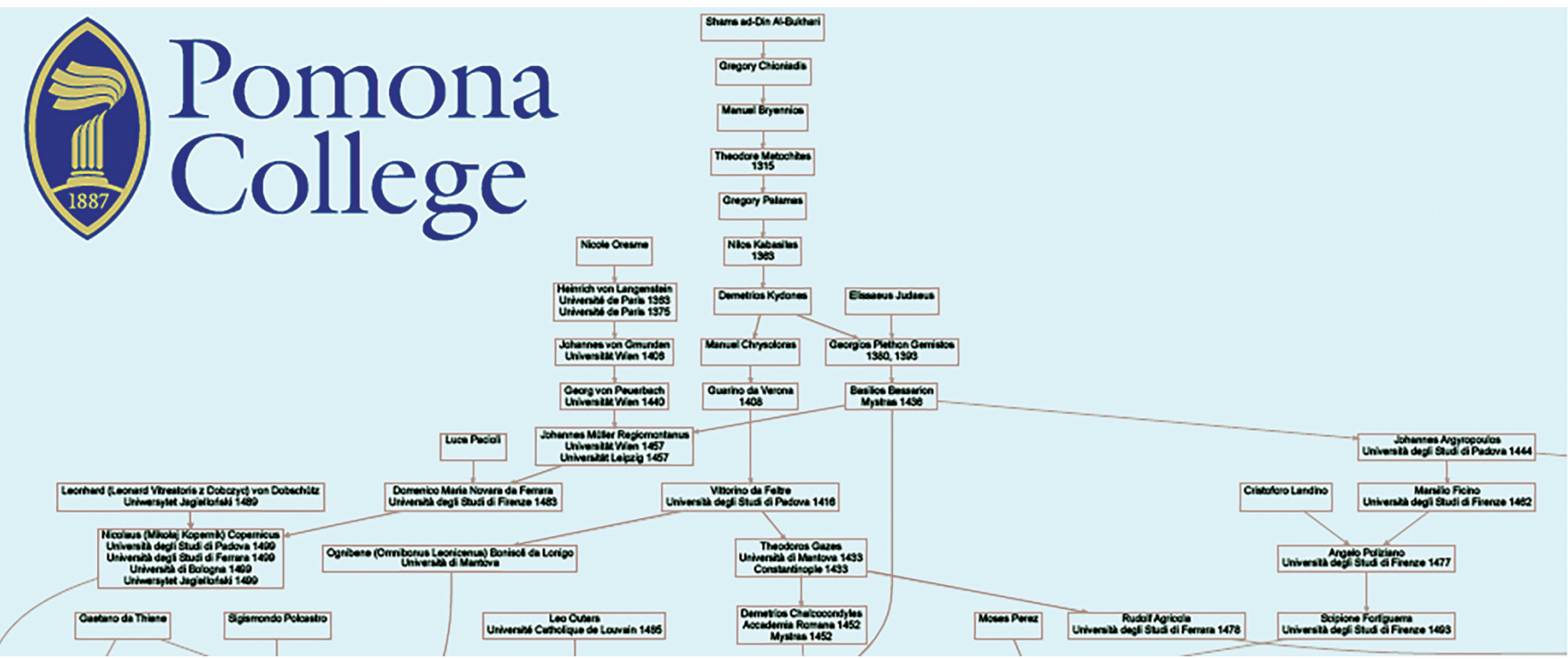

Figure 3. The start of the ancestry of the Pomona faculty from a larger custom poster from the Mathematics Genealogy Project.

Hilbert had 75, Blackwell 66, and Stanley 60. Kaplansky's 55 sees him come in at position eighty-seven.

\section{Poster Children and Relative Value}

Both individuals and departments with an interest in their heritage like to see the highlights displayed in family trees, and MGP offers customized mathematical genealogy posters (for a fee). Mitch notes, "Individual posters have proved popular for birthday and retirement conferences as well as graduation gifts." Stephan Garcia of Pomona College agrees: "We just purchased a huge MGP poster for the whole department a few weeks ago." (See Figure 3.) Likewise, Michael Wolf of Rice says, "When I was department chair, I did purchase a departmental version so as to visually depict the intellectual heritage of the department to visitors."

So who uses MGP other than for casual browsing or ancestral bragging? Certainly, Wikipedia editors: many of the Wikipedia pages on modern-era mathematicians include an external link to the corresponding MGP entry, and some of the information listed derives from what is found at that link. Then there are academic journal editors. Norman Richert, managing editor of Mathematical Reviews, is on the advisory board of MGP. He shares the views of other editors with regard to the usefulness of MGP in "giving a picture of who people are and where they fit in the mathematical spectrum," as well as when trying to avoid possible conflicts of interest. He raises another point. "As I think about authors in terms of inviting them to be reviewers, $\mathrm{I}$ am interested if they have a degree (many more $\mathrm{PhD}$ students are publishing papers during their studies than in the past); the MGP links on the author profile pages in MathSciNet answer that with high (but not 100 percent) probability."
Janet Beery (University of Redlands) and Carol Mead (archivist for the Archives of American Mathematics at UT-Austin) used MGP in gathering information for their Convergence article "Who's That Mathematician? Images from the Paul R. Halmos Photograph Collection" (over sixty webpages). Carol says, "It's a great reference tool for me. I use it to identify or verify someone. And, as a nonmathematician, it helps me learn more about mathematicians I'm not familiar with." Lev Borisov of Rutgers adds, "I think it will be an invaluable tool for math historians. I can also imagine it being useful to social scientists and government agencies."

\section{Hatched, Matched, and Dispatched}

The three mainstays of traditional genealogy are the documentation of birth, parenthood, and death, and the academic versions of the first two are reflected in the MGP. However, while neither life nor death details are recorded there, the site still proves useful for obituary writers, just as ordinary family trees do. "When a mathematician dies, we like to include where The valute of he or she got the $\mathrm{PhD}$, when it was granted, and sometimes who the advisor was," notes MGP to the AMS Public Awareness Officer Mike Breen, MGP to the AMS Public Awareness Officer Mike Breen, community is of..." items on the AMS website. "We like to enormous. that many will recognize. I think it allows the reader some insight into the person's history, just as MGP itself does. Someone who is two generations from Kolmogorov, for example, deserves mention."

Norman Richert again: "The value of MGP to the community is enormous. Mathematics research has always involved a web of people. The collaboration graph in MathSciNet gives indications of this web. And so does the advisor/student graph in MGP. Mathematicians have 
long been interested in these connections, possibly more than any other science. There was a time in the early days when some seemed to think it was a silly hobby of Harry. Most people, I think, have come to appreciate its value; certainly, the AMS has."

\section{Limits}

Naturally, there are limits to MGP's usefulness. It can only go back so far in time, and it only tracks a certain formal type of mathematical training. Like traditional genealogy, MGP also tends to turn a blind eye to off-the-record progeny. There are quite a few people who feel that somebody other than their official supervisor was their real mathematical father or mother, and as in ordinary families "parents" and "children" don't always see eye-to-eye about the exact relationship. There are several reasons why the formal record may not match the reality, ranging from institutional to personal, and in most cases such anomalies are likely to remain undocumented online.

Furthermore, younger people tend to be less interested than their elders in genealogy of any sort, and they don't always respond to nudges to get themselves added to MGP. As in all spheres of STEM record keeping, it is important that underrepresented groups in mathematics are as present as possible in MGP, even if their minority status is invisible to a casual viewer: no age, gender, nationality, photo, or identifying information other than name is indicated for the entries. (The country flag shown for each degree represents today's country designation for the degree-granting institution.) For these reasons alone, it is especially important that advisors and departments regularly submit, correct, and update information at MGP.

Finally, there is the question of accuracy: anybody can submit data to MGP, and in most cases it is accepted on faith. There are certainly instances where $\mathrm{X}$ is believed to have been a student of Y "with high probability," although it cannot be proved; sometimes neither the theses in question nor the corresponding official records survive.

\section{Structure and Support}

Those curious about the structure of the graph that MGP forms can find some information at the website. Around 2008, Bud Brown of Virginia Tech noticed that the MGP graph is nonplanar and drew the subgraph in Figure 4 showing this fact.

As of July 2016, about 90 percent of the entries of MGP formed a single connected component, of which about 75 percent was taken up by roughly 7,300 root vertices (people with no listed advisor) and roughly 137,000 leaves (people with no documented students). Then there are isolated vertices, such as that of Irish mathematician William Rowan Hamilton. He seems to have been included merely as a courtesy: he didn't have a $\mathrm{PhD}$ (or formal descendants). Problematically, his flagless entry includes "Advisor: Unknown" and "No students known," the first perhaps suggesting that it's just a case of doing more digging. The designation "None" would be more helpful in both cases, and in general it would be nice to have a way to distinguish between (possibly empty) lists of academic offspring that

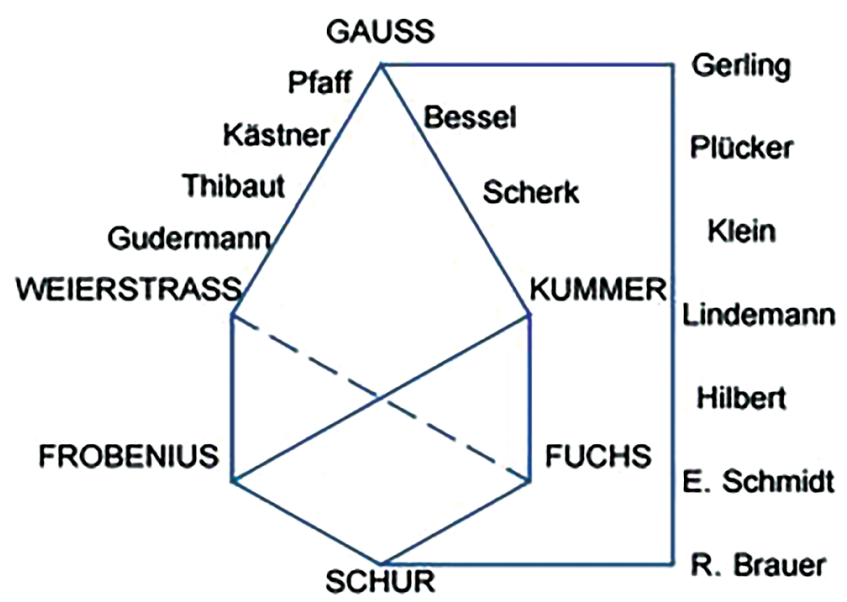

Figure 4. Proof without words. The MGP graph is nonplanar, as it contains this subgraph homeomorphic to $K_{3,3}$, connecting Gauss, Frobenius, and Fuchs to Weierstrass, Kummer, and Schur.

are known to be complete and ones for which more data might conceivably be added down the road.

Some mathematics departments provide (implicit) structured support for MGP by proudly displaying online lists of all their successful graduate students, going back to the earliest times, two notable examples being those at the University of British Columbia ${ }^{2}$ and University College Cork in Ireland. ${ }^{3}$ Of course, that leaves to others the nontrivial work of submitting the relevant (missing) thesis information to MGP, and in the case of UCC, yours truly has had a go at it.

Most universities' websites provide search engines to track the existence (and sometimes also the text) of dissertations, although that can be limited to more recent degrees. Frustratingly, many do not allow searches by subject or advisor; indeed, some institutions seem to keep no record of either. Caltech's site thesis . 1ibrary . caltech.edu is one of the best, even allowing searches by advisor or committee members. It might make a nice student project at such institutions to ensure that the appropriate theses are all added to MGP.

While MGP is entirely dependent on voluntary submissions of data to become larger and more accurate, it also needs financial support. Managing Director Mitch Keller notes that "Everyone involved with the MGP is grateful for the support of the mathematical community over the past twenty plus years, and we look forward to continuing to be a valuable resource for many years to come. The MGP has long used donated funds to employ student workers to help process data. Since the project moved to NDSU in 2002, these have mostly been graduate assistants doing work in addition to their regular teaching duties. The budget since 2008-2009 has ranged from $\$ 6,000$ to $\$ 9,000$ annually, with roughly half of that being payroll costs for the data graduate assistants each year. The rest

\footnotetext{
${ }^{2}$ https://www. math. ubc. ca/Grad/gradA1 umni . shtm1

${ }^{3}$ www. ucc.ie/en/matsci/postgraduate/
} 


\section{COMMUNICATION}

is typically travel and printing of posters. We are working on increasing the amount of donations received each year to further improve the project. Right now, our backlog stands at a month because of staffing limitations that are largely funding related, and we are already needing to start thinking about the costs of attending ICM in 2018."

Donations to support the ongoing work of the MGP are encouraged, either as one-time gifts (perhaps even a legacy gift) or as recurring donations. Using the Donate button on the main page sidebar menu is one way to contribute.

\section{Credits}

Figures 1-3 are courtesy of the Mathematics Genealogy Project. Figure 4 is courtesy of Ezra Brown.

Photo of Colm Mulcahy is courtesy of Colm Mulcahy.

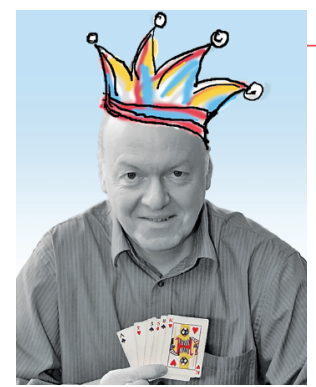

Colm Mulcahy

\section{ABOUT THE AUTHOR}

Colm Mulcahy of Spelman College, Atlanta, is the author of the book Mathematical Card Magic: Fifty-Two New Effects (A K Peters/CRC Press, 2013), vice president of Gathering 4 Gardner, and the creator and curator of the online Annals of Irish Mathematics and Mathematicians.

\section{American Mathematical Society}

\section{(III}

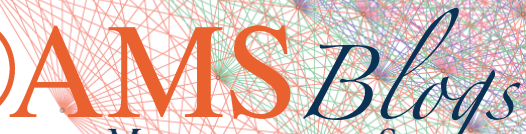

AMERICAN MATHEMATICAI SOCRETY

\section{Beyond Reviews}

\section{A blog about MathSciNet}

From the Executive Editor of Mathematical Reviews, Edward Dunne

A blog created to highlight the innovative features of MathSciNet. Updates will include particularly informative reviews and will discuss tips and tricks for navigating MathSciNet, all with the goal of being helpful to users both old and new.

\section{blogs.ams.org/beyondreviews}
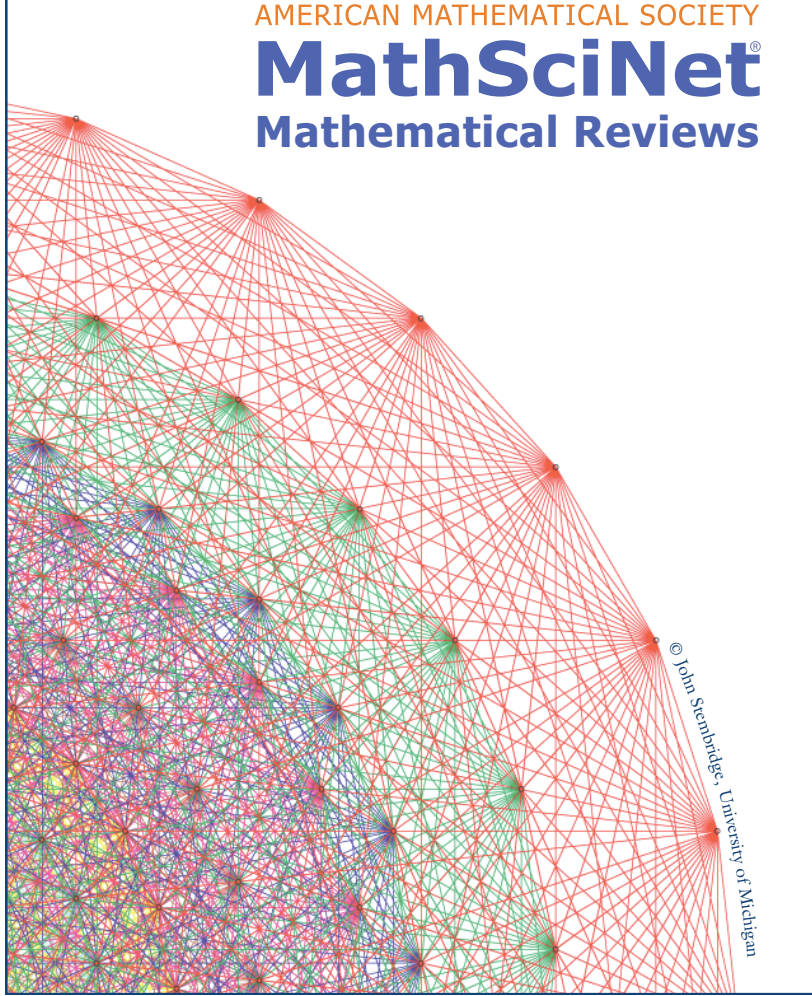